American Journal of Applied Sciences 1 (4): 302-308, 2004

ISSN 1546-9239

(C) Science Publications, 2004

\title{
Economic Impact of E. Coli O111 Outbreak in 1995 in Australia
}

\author{
${ }^{1}$ Shahjahan Ali Khandaker and ${ }^{2}$ Mohammad Alauddin \\ ${ }^{1}$ Health Economics Unit, Ministry of Health and Family Welfare \\ Government of Bangladesh, Dhaka, Bangladesh \\ ${ }^{2}$ School of Economics, The University of Queensland, Brisbane, QLD. 4072, Australia
}

\begin{abstract}
Increased incidence of food-borne illnesses is a matter of significant concern for the community and the government alike. An outbreak of E. coli O111 that occurred in Australia in 1995 affected 200 people of whom 22 developed HUS while one person died. This study analyses the economic costs of the outbreak. The total cost of the outbreak is estimated to be A $\$ 5$. 61 million. Productivity loss represented the highest percentage of outbreak costs $(66 \%)$ due to death, disability and chronic illness. The direct medical costs contributed 33\%. The estimated loss could be even higher if all costs could be quantified. Nevertheless, the findings provide an idea of the policy maker regarding the extent and nature of the damage that could result from an outbreak. The severity of the damage warrants allocation of necessary resources to prevent such occurrences.
\end{abstract}

Key words: E. coli Outbreak, Food-Borne Illness, Economic Costs, Productivity Loss

\section{INTRODUCTION}

There has been an increasing trend of foodborne illnesses and outbreaks throughout the world. These are a matter of concern for the community and the government alike. Foodborne illnesses entail costs not only to the ill person and the immediate family, but also are a cause of major economic cost to the food industry in producing and marketing food, reducing consumer confidence and to public health regulations and enforcement that set ground rules for food production and preparation ${ }^{[1,2,3]}$. Estimation of costs of foodborne illness is thus important for policy decision and allocation of necessary resources to undertake a suitable control program. Several studies on economic impact have been undertaken in the $\mathrm{UK}^{[2,4]}$, the $\mathrm{USA}^{[5,6]}$ and Canada $^{[7]}$.

Australia has experienced outbreaks of foodborne diseases since 1980. The major outbreaks reported are Norwalk virus outbreak in 1991, the South Australian E. coli O111 outbreak in 1995, Salmonella outbreak 1996 in Victoria and Queensland and Hepatitis A oysters outbreak 1997 in New South Wales ${ }^{[8]}$. Although a preliminary estimation of costs of total foodborne illnesses was made ${ }^{[8]}$, there does not seem to have been any comprehensive economic study in this area. This study seeks to fill this gap by estimating socioeconomic costs of the E. coli O111outbreak that occurred in Australia in 1995.

The outbreak-a brief overview: An outbreak of Escherichia coli O111 occurred in South Australia in January to February 1995. About 200 people were affected by Haemorrhagic Colitis (HC), 23 children developed Haemolytic Uraemia Syndrome (HUS) with one death occurring. The South Australian
Communicable Disease Control Unit of the Health Commission (SACDCU) issued a press release noting the link of this outbreak with a sausage prepared from beef $^{[9]}$.

A locally produced fermented sausage (mettwurst) was incriminated by epidemiological and microbiological investigation. The outbreak occurred as a complication of infection associated with the consumption of the uncooked, semi-dry, fermented sausage ${ }^{[10,11]}$.

The Women's and Children's Hospital, Institute of Medical and Veterinary Science and The National Centre for Epidemiology and Population Health at the Australian National University reported the outbreak on the basis of their investigation results. E. coli O111 was identified from the outbreak and from sausages ${ }^{[10,11]}$.

\section{MATERIALS AND METHODS}

The Cost of Illness (COI) approach is used to estimate direct medical costs and productivity loss associated with the outbreak due to E. coli $\mathrm{O} 111$ infection in 1995. The method simply conveys the aggregate burden of illness on the society. Both direct and indirect costs are estimated from the outbreak. Physician visit, hospital costs, disease investigation, dialysis and kidney transplant are considered as direct costs and loss of productivity from missing work for both patients and parents/care and travel costs are measured as an indirect cost. The estimated costs depend on the severity of illness as well as the age of the patient. The economic factors, which may influence the costs of illness, are identified. The calculations of the estimates are based on some assumptions that are made from relevant studies in the literature. 


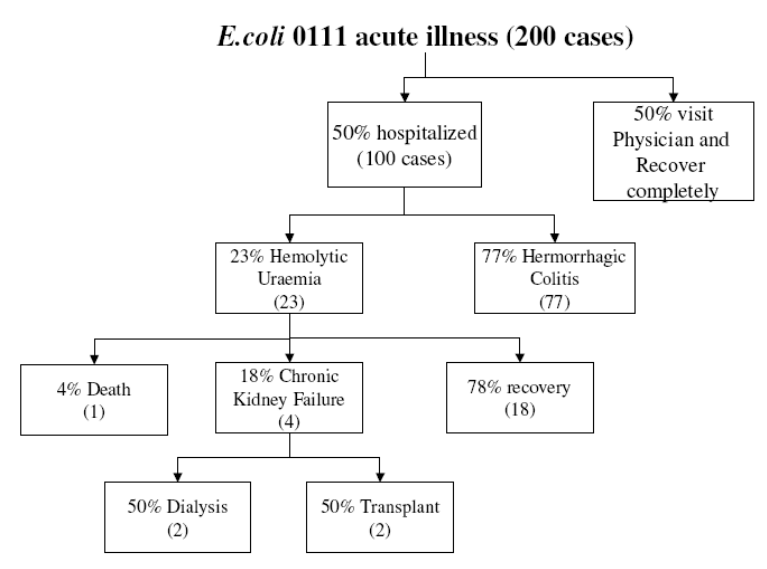

Fig. 1: Decision Tree for E. Coli Outbreak in 1995 in Australia

Estimation of illness: To estimate the number of cases of the outbreak a decision tree was constructed based on the previous references and the available information about the outbreak (Fig. 1). The number of patients in different severity groups is estimated from the decision tree.

Total number of cases: It was reported that 200 cases developed bloody diarrhoea, abdominal cramp and vomiting from the outbreak ${ }^{[12]}$. This study uses this as an estimated total number of cases of the outbreak.

Mild case: From the decision tree it is assumed that 100 affected people visited a physician and did not require hospitalization due to a lesser degree of severity of illness.

Acute case: It is assumed that all acute cases were required to be hospitalized since the outbreak. Seventyseven Haemolytic Colitis (HC) and 23 Haemolytic Uraemic Syndrome (HUS) patients were treated for acute illness.

Chronic case: It was reported that 4 patients out of the 23 Haemolytic Uraemic Syndrome (HUS) patients ${ }^{[9,12]}$ suffered chronic renal failure.

Death: Death of one child was reported from the acute haemolytic uraemic syndrome ${ }^{[9]}$.

The number of hospitalized cases: As there is no information about the proportion of patients admitted to hospital from the acute phase of the outbreak, this study assumes that all acute patients were required to be hospitalized. Therefore, 100 patients (50\%) were hospitalized from the outbreak. It is also assumed that $50 \%$ of the cases were recorded in hospital and the physician recorded the remaining $50 \%$ of the cases.
Age and sex distribution ${ }^{[2]}$ : Reported that almost 50\% of the cases were under 5 years and $70 \%$ under 16 years ${ }^{[9]}$. Reported the median age of 23 patients was 4 years. Following this, assumptions are made (decision tree) for this study and results presented in Table 2a.

Direct medical costs: Acute illness medical costs include both hospital and non-hospital costs, cabin charges, physician fees, fluid therapy, medicines and drugs, pathological tests, blood transfusion and other related treatment except surgical intervention ${ }^{[13]}$. The medical costs of patients at hospital stay are computed from the data provided by Australian RefinedDiagnostic Related Group (AR-DRG) version 4.2. ${ }^{[13]}$. The following direct costs are estimated from the outbreak.

Non-hospitalization costs: It is assumed that 50\% (100) of the patients affected with mild and moderate infection visited a physician. Following ${ }^{[14]}$, it is assumed that these patients required on average two physician consultations, one simple diagnostic stool test and some medicine including oral saline. The consultation fee of physician is estimated at $\mathrm{A} \$ 22$ from the data of Medibank reimbursement rate (Personal communication with the local Medibank Private Office, Queensland). The cost for stool test is estimated at A \$35. 00 (Personal communication with Laboratory Section, Cleveland Hospital, Queensland).

Hospitalization costs for Acute HC: Patients with Hemorrhagic Colitis (HC) were hospitalized for bloody diarrhea, dehydration and severe abdominal cramps. It is reported that a gastroenteritis patient requires at most eleven days of hospitalization ${ }^{[15]}$. Therefore, this study assumes ten day hospital stay to estimate the costs of acute illness. Using the formula of AR-DRG ${ }^{[13]}$, the hospital costs of a patient are calculated at A $\$ 1,359$ for 10 days ${ }^{[16]}$.

Hospitalization costs for Acute HUS: Of the estimated 22 HUS patients, sixteen $(70 \%)$ required dialysis in acute stage. The average length of hospital stay by the acute HUS patient was estimated at 26 days ${ }^{[17]}$. Following ${ }^{[17]}$, this study uses the assumption of an average 26 day hospital stay. The cost for the acute HUS patient is estimated at A \$7,464 from AR-DRG data ${ }^{[13]}$.

Chronic illness medical costs: It is reported that a proportion of HUS patients suffered chronic kidney failure, requiring dialysis, kidney transplants and drug therapy. Estimated medical costs of chronic illness are calculated by summing the costs of these three items. From available data ${ }^{[9]}$, this study assumes that $18 \%$ (4 patients) suffered renal failure and TTP (Thrombotic thromcytopenic pupura). Previous studies ${ }^{[5,23]}$ reported that at least 6 months haemo-dialysis were required for 
a chronic HUS patient before undertaking kidney transplant or the start of home dialysis. This study assumed that one patient went to kidney transplant from the second year, one of the third year and one started with home dialysis from the third year. One patient continued to suffer from TTP. The annual hospital dialysis costs for a patient is $\mathrm{A} \$ 42,348$ and home dialysis is $\mathrm{A} \$ 29,571^{[13]}$. Costs for 10 months of the initial year are estimated at $\mathrm{A} \$ 37,790$. The costs for a kidney transplant are estimated at $\mathrm{A} \$ 21,594$ with an average length 11 days of hospital stay ${ }^{[13]}$. It is reported that TTP is a disease similar to HUS but is associated with some neurological complications in adult ${ }^{[25]}$. As there is no reference to treatment costs, it is assumed that the cost for a HUS patient is equivalent to that of a TTP patient. Assuming a 77 year statistical life ${ }^{[21]}$ home dialysis costs are estimated from 7 years and discounted at $5 \%$. The assumptions used for calculations are set out in Table 1.

Productivity loss from acute infection: Productivity loss measures the decline in production or output resulting from illness of the patient as well as productivity loss from parents/career who missed work to care for the sick patients. Regardless of gender or race daily average earning is used as a proxy for valuing the daily forgone productivity by a worker. It is assumed that the age groups between 0-15 are not in the labor force and parents or caretakers were required to look after these age groups. Assuming a 73\% labor participation rate for a typical age group 16 years and above labor earning per day is estimated at $\mathrm{A} \$ 160.75$ from the weekly wage of $\mathrm{A} \$ 800.06$ dollars ${ }^{[18]}$. The following assumptions underlie the estimate of productivity loss.

Loss from Non-hospitalized patients: Patients who were not hospitalized were taken care of either by parents or caretaker. Following ${ }^{[5]}$ it is assumed that parents or caretakers missed 4 working days. Parents encountering productivity loss from missing work were assumed to be only for the 0-15 year age group, while the 16 and above age group encounter productivity loss from missing their own work.

Loss for Hospitalized HC patients: It was reported that recuperation period of HUS patient to be twice the hospital stay ${ }^{[5]}$. Following ${ }^{[5]}$ this study assumes that 30 days were required for full recovery. Adjusted with weekend total 22 days' work was missed by parents. Like a non-hospitalized patient it is assumed that parents encountered productivity loss only for the $0-15$ year age group while patients 16 years old or older encountered productivity loss from missing their own work.

Loss for Hospitalized HUS patients: Following ${ }^{[5]}$ like HC patients the same assumption is made for the HUS patients and an average 78 days were assumed to be required for recuperation. Adjusted with a weekend caretaker or parent missed 56 days. The same assumptions as hospitalized $\mathrm{HC}$ patients are made to estimate loss from hospitalized HUS patients.

Loss from premature death: One 4 year child died from acute $\operatorname{HUS}^{[9]}$. Productivity loss from this premature death is measured based on the method $\mathrm{in}^{[19]}$. The loss is measured from age 4 years old to expect average life 77 years old ${ }^{[20]}$. The study uses $A \$ 66,699$ annual labor and non-labor income and household opportunity cost $5 \%$ with 1.6 risk aversion factor ${ }^{[5]}$. Annual per capita labor and non-labor income is estimated from total national labor and nonlabor income $\mathrm{A} \$ 650,675$ million ${ }^{[21]}$ to labor force participation rate for $73 \%$ percent for the year $2001^{[22]}$. The VOSL (value of statistical life) loss ${ }^{[19]}$ is given as:

$\operatorname{VOSL}=\left(\sum_{t}^{T} \frac{Y_{t}}{(1+r)^{t}}\right) \alpha$

Where:

$\mathrm{T}=$ Remaining life time income

$\mathrm{t}=$ A particular year

$\mathrm{Y}_{\mathrm{t}}=$ After tax income from labor and non-labor sources

$\mathrm{r}$ = Household opportunity cost of investing in risk reducing activities

$\alpha=$ Risk aversion factor

Productivity loss from chronic illness due to HUS: Parents/career Loss: Patient and parents/caretaker both encounter productivity losses from chronic illness. Parents encounter loss of time spent to perform dialysis for the chronic dialectic patient. It is assumed that one patient went to kidney transplant from the second year, one of the third year and one started with home dialysis from the third year ${ }^{[5]}$. Reported that parents encountered $45 \%$ (18 hours out of 40 hours in a productivity loss in the initial year followed by a $1 \%$ reduction to the subsequent year. Following ${ }^{[5]}$, this study uses the same assumption. The weekly average wage rate is used to estimate the yearly loss, considering the labor participation rate and age of the parents. The productivity loss is calculated for 12 years when 4 years of age patient become 16 years and can continue self dialysis. The reduction stream of productivity loss was converted to present value at 5\% discount rate.

Table 1: Assumption Made for Estimating Cost for Chronic Illness Medical Costs from South Australian Outbreak 1995

\begin{tabular}{|c|c|c|c|}
\hline Year & $\begin{array}{l}\text { Actual } \\
\text { Year }\end{array}$ & $\begin{array}{l}\text { No. of } \\
\text { Dialysis } \\
\text { Patients }\end{array}$ & $\begin{array}{l}\text { No. of } \\
\text { Kidney } \\
\text { Transplant } \\
\text { Patients }\end{array}$ \\
\hline 1 & 1995 & 4 (10 months) & - \\
\hline 2 & 1996 & 3 & 1 \\
\hline 3 & 1997 & $\begin{array}{l}1 \text { (home dialysis) } \\
1 \text { (TTP) }\end{array}$ & 1 \\
\hline
\end{tabular}


Patient loss: Patients encountered productivity loss from their disability due to chronic dialysis and kidney transplant. Following ${ }^{[23]}$ the disability loss due to dialysis and kidney transplant is calculated from age 16 to expected average life 77 years $^{[20]}$ in 1995 by adjusting the individual annual earnings by age. It is assumed that dialysis patients lost productivity by $37 \%$ aged between 16 and 40 years, by $46 \%$ if aged between 40 and 64 years and 5\% if aged 65 years and above. The loss for kidney transplant patient is $23 \%$ for the 16 40 year age group, 39\% for the 40-64 year age group old and $13 \%$ for 65 plus years old ${ }^{[23]}$. Both kidney transplant and chronic dialectic patients required medicine therapy to avoid some complications. An average medicine cost is estimated at $\mathrm{A} \$ 3,000$ (Personal communication with a physician, at Redland Hospital, Queensland).

The estimated productivity loss from chronic patients is computed by summing the losses from dialectic patient and kidney transplant and discounted them at $5 \%$ to derive present value.

Travel costs: It is assumed that at least $50 \%(n=50)$ of the hospitalized patients travelled by Ambulance and $50 \%$ travelled either by family car or by taxi. Patients below 16 years were assumed to be visited by parents or career at least once a day. As a result two journeys are assumed to have taken place. The ambulance costs per journey is $\mathrm{A} \$ 706$ for the emergency patients ${ }^{[15]}$. The cost of one journey by car is estimated at $\mathrm{A} \$ 15$ including parking costs assuming an average travel distance $50 \mathrm{kms}$.

Sensitivity analysis: The estimate in this study is based on the assumptions stated earlier. The results of the estimate may be subject to error. To accommodate the likely error the estimated result is subjected to sensitivity analysis according to the assumption provided in Table $3 \mathrm{~b}$.

Table 2a: Number of Patients by Category

\begin{tabular}{|c|c|c|}
\hline Patient category & Number & $\%$ \\
\hline Visit to physician $^{1}$ & 100 & 50 \\
\hline Hospitalised $^{1}$ & 100 & 50 \\
\hline Total: & 200 & 100 \\
\hline \multicolumn{3}{|l|}{ Hospitalized: } \\
\hline Haemorrhagic colitis ${ }^{1}$ & 77 & 77 \\
\hline Haemolytic uraemic syndrome & 23 & 23 \\
\hline Total: & 100 & 100 \\
\hline \multicolumn{3}{|l|}{ Haemolytic uraemic syndrome: } \\
\hline Renal failure $^{2}$ & 4 & 17.39 \\
\hline Death $^{3}$ & 1 & 4 \\
\hline Recovery & 18 & 78 \\
\hline Total $23^{\circ}$ & 100.00 & \\
\hline
\end{tabular}

${ }^{1}$ According to assumptions in decision tree in Fig. 1

${ }^{2}$ Following ${ }^{[12]}$

${ }^{3}$ Following ${ }^{[9]}$

Table 3a: Summary Costs of E. coli O111 Outbreak in 1995, Australia: Most Probable Scenario

\begin{tabular}{|c|c|c|c|c|}
\hline Cost items & Costs in $\mathrm{A} \$$ & $\%$ in sub-total & $\%$ in total & Average cost $(n=200)$ \\
\hline \multicolumn{5}{|l|}{ Direct medical costs } \\
\hline $\begin{array}{l}\text { Non-hospitalized patient } \\
\text { HC patients: }\end{array}$ & 8900. 00 & 0.51 & 0.16 & 44.50 \\
\hline Hospital costs & 104643. 00 & 5.96 & 1.86 & 44.50 \\
\hline \multicolumn{5}{|l|}{ Acute HUS patient: } \\
\hline Hospital costs & 171672.00 & 9.78 & 3.06 & 858.36 \\
\hline Chronic illness & 1546996.94 & 83.76 & 27.54 & 7734.98 \\
\hline $\begin{array}{l}\text { Ambulance/transport } \\
\text { costs }\end{array}$ & 37550.00 & 1.06 & 0.67 & 187.75 \\
\hline $\begin{array}{l}\text { Sub-total } \\
\text { Indirect cost/Productivity Loss }\end{array}$ & 1869761.94 & 100.00 & 33.28 & 9348.81 \\
\hline $\begin{array}{l}\text { Productivity loss from Non- } \\
\text { Hospitalized patients }\end{array}$ & 64300.00 & 1.82 & 1.14 & 321.50 \\
\hline Loss from hospitalized patients & 479356.50 & 7.70 & 8.53 & 2396.78 \\
\hline Parent loss from Chronic patient & 406426.41 & 11.49 & 7.24 & 2032.13 \\
\hline Loss for patients disability & 580682.14 & 15.27 & 10.34 & 2903.41 \\
\hline Loss from premature death & 2180488.07 & 61.64 & 38.82 & 10902.44 \\
\hline Travel costs by relatives & 36480.00 & 1.03 & 0.65 & 182.40 \\
\hline Sub-total & 3747733.12 & 100.00 & 66.72 & 18738.67 \\
\hline Grand total & 5617495.06 & & 100.00 & 28087.48 \\
\hline
\end{tabular}

Table 3b: Summary Costs of E. coli O111 Outbreak in 1995, Australia: Scenarios Involving Sensitivity Analysis (Figures in million Australian dollars)

A. Cost overrun scenario

Percentage increase in most

probable scenario of A $\$ 5.61$ million

$10 \%$

$20 \% \quad 30 \%$

$6.18 \quad 6.74$

7.3

B. Cost under run scenario

Percentage decreases on most

probable scenario of A $\$ 5.61$ million

$10 \%$

5.06

$20 \%$

4.49
$40 \%$

7.86

$50 \%$

8.43 


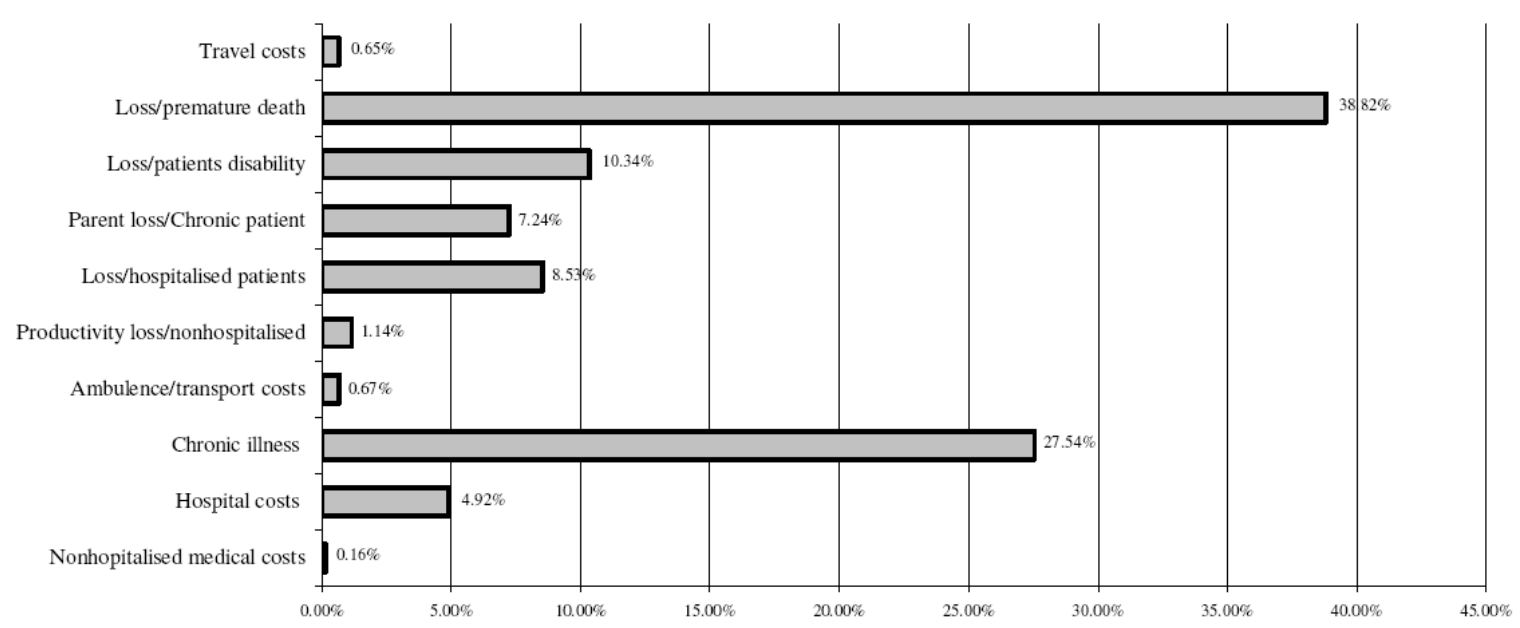

Fig. 2: Summary of Costs for the E. Coli Outbreak in 1995, Australia

\section{RESULTS}

The summary results of the estimated total costs of the outbreak are presented in Table 3. The results show that an estimated loss of $\mathrm{A} \$ 5.61$ million is incurred due to the outbreak. If the total cost direct medical cost is estimated at $\mathrm{A} \$ 1.87$ million (33.28\%) and estimated indirect cost is $\mathrm{A} \$ 3.74$ million (66.72\%). Of the total costs highest costs incurred from the loss of a life which accounted for $38.82 \%$ of the total costs followed by loss from chronic illness (27.54\%), disability (10.34\%) loss of productivity from a hospitalized patient $(8.53 \%)$ as shown in Fig. 2.

The bulk of direct costs $(83.76 \%)$ was associated with chronic medical costs followed by hospitalization costs $(9.78 \%)$ from HUS patient and $5.96 \%$ from the HC patient (Table 3a).

More than $60 \%$ of the productivity loss is due to loss of future productivity as a result of death. Productivity loss from chronic patients (15.27\%) due to their disability, while parents' productivity losses from chronic patient accounted for $11.49 \%$ and loss of the hospitalized patients $7.7 \%$ (Table $3 \mathrm{a}$ ). The result of the sensitivity analysis shows that the estimated total costs may vary from $\mathrm{A} \$ 2.8$ million to $\mathrm{A} \$ 8.4$ million (Table 3b).

The medical costs are estimated for 200 patients according to the severity of the illness at $\mathrm{A} \$ 0.28$ million, chronic therapy required in 4 patients and estimated at $\mathrm{A} \$ 1.54$ million. Productivity loss of 100 nonhospitalized patients is estimated at $\mathrm{A} \$ 0.064$ million and from 100 hospitalized patients estimated at A $\$ 0.47$ million. Parent's productivity losses from 4 chronic patients are measured at $\mathrm{A} \$ 0.40$ million and patient productivity loss due to disability measured at A $\$ 0.58$ million. Travel costs encountered by visitor to hospitals are measured in 100 patients at $\mathrm{A} \$ 0.036$ million and ambulance costs for 50 journeys at $\mathrm{A} \$ 0$. 037 million.

\section{DISCUSSION}

The estimated total cost of the outbreak amounted to A\$5. 61 million. Average costs per patient A $\$ 28,089$ with an assumed $50 \%$ hospitalization rate.

The results of the study indicate that productivity loss contributes significantly to the total costs. Productivity losses comprise those from parents or caretakers for taking care of sick patients while in hospital and at home until recovery; losses from time spent due to haemo-dialysis of chronic patients, losses from travel costs to commute hospital. This also takes into account losses from disability due to chronic dialectic and kidney transplant recipient patients. The findings of this study are supported by ${ }^{[3,14,24]}$. Eighty seven percent of costs are incurred due to productivity loss from E. coli O157: $H 7$ foodborne illness in the USA $^{[23]} 94 \%$ costs were due to productivity loss in UK ${ }^{[2]}$. However, in Japan less than $40 \%$ of the total costs were due to loss of productivity. This lower contribution of productivity loss in Japan was due to exclusion of death from estimation.

The productivity loss is greatly influenced by the premature death, which has contributed $61 \%$ to the productivity loss. A higher level (97\%) of the productivity losses were due to premature death in $\mathrm{USA}^{[23]}$ and $76 \%$ loss were due to premature death in $\mathrm{UK}^{[2]}$. The variation of productivity loss due to premature death might be due to variation of mortality rate from the outbreak.

This estimate includes loss of lifetime income of one premature death that resulted from acute illness. If the number of deaths increased the productivity losses and the total costs from the outbreak would have been higher. This study estimates the value of statistical life from 4 years to 77 years at $\mathrm{A} \$ 2.2$ million by using ${ }^{[19]}$ method. The future value of life varies across the studies depending upon the methods used, labor and 
non-labor income, opportunity costs household expenditure, risk aversion factor and life expectancy across the population. ${ }^{[14]}$ estimated VOSL at A\$ 1.2 million in 1993 dollar at 3\% discount rate in the USA while ${ }^{[2]}$ used $£ 2.3$ million to value the life from UK Department of Transport at 1995 price to estimate the value of lives lost in rail track accidents. Age of the patient greatly influences the value of statistical life and the younger has a higher value on life than the older. ${ }^{[14]}$ used an average age 4 years whereas ${ }^{[2]}$ used actual age from their survey. The present study uses the actual age of the patient.

Chronic patients account for a significant cost of the productivity loss than the acute patients. The losses are associated with productivity loss of parent/caretaker to undertake dialysis for the initial year and subsequent year until 16 years when the sickest patients himself can carry out dialysis. A remarkable proportion of costs are also incurred from disabled patients. These are involved due to continued dialysis or due to a kidney transplant. This study estimates these losses from two-dialectic patient and two transplant recipient patient by using the assumption from ${ }^{[14]}$. Precise estimation of loss associated with disability in the real world is really difficult and there is not sufficient information on this estimation. But there are many losses associated with disability. However, estimation of costs is influenced by weekly income and labor participation force and life expectancy between the countries. In the USA, loss from chronic patients contributed 5\% to the total costs ${ }^{[14]}$, while in UK $73 \%$ to the total $\operatorname{costs}^{[2]}$. In contrast, in this study chronic patient contributes $27 \%$ costs to the total. This variation might be due to the differences in assumption and differences in proportion of chronic patients in the studies.

Hospitalization costs have an impact on medical costs as well as on total costs. These costs depend on the length of hospitalization and the recuperation period. The longer the stay in hospital the higher the medical costs and parents'/caretakers' productivity losses. Hospital stay and recuperation period also depends on the severity of the illness. Hospitalization times increase, as the case turns into chronic. An average 6.5 day hospital stay were used for USA ${ }^{[5]}$, in contrast to 25.4 days for the UK ${ }^{[2]}$. $^{[17]}$ estimated an average hospital stay of 26 days for HUS patients and highest 11 days for gastroenteritis ${ }^{[15]}$. However, the variation in hospital stays among countries might be due to variations of strains of $E$. coli and geographical distributions. With medical costs, the higher proportions of costs are associated with only 4 chronic patients out of 200 patients. The higher chronic medical costs resulted from dialysis and kidney transplant of the chronically ill patients.
However, the estimated costs could be even higher if losses from further complications and resulting death due to this outbreak were taken into consideration. ${ }^{[14,2]}$ reported that there might be further complications from E. coli O157: H7 outbreak but this study did not estimate these costs due to lack of data.

This study did not include the estimation of the costs of public health sector, food industry costs, psychological and overactive behavior costs. It is obvious that public expenditure was incurred for investigation and control of the outbreak. The estimation of pain and suffering of family and friends is cumbersome due to lack of appropriate data. Food industry encountered a significant loss due to the outbreak as mettwurst was identified as a suspected vehicle for the outbreak. It was reported that mettwurst sale decreased to $40 \%$ throughout Australia and 400-500 small businesses closed down as a result $^{[26]}$. However, the estimated losses from the outbreak could have been much higher if these were included in the estimate of the present study. The inability to estimate the above loss has been criticized as a weakness of the cost of illness methods and it, therefore, does not reflect the true social costs and only measures the lower bound of the willingness to pay of society ${ }^{[14,23]}$.

\section{CONCLUSION}

The results of the study show that Australian society has incurred a substantial loss from the E. coli outbreak in 1995 in South Australia. Some of the losses are quantifiable while others may not be. A premature death and chronic patients contributed to the majority of the burden to the society. The estimated loss is from a single outbreak of $E$. coli and may be huge if loss from other foodborne illness and outbreaks are taken into consideration.

The results of the study provide an idea of the policy maker regarding the extent and nature of the damage to the society due to an outbreak. Considering the severity of the damage necessary resources can be allocated to prevent such damages.

This study suffers from a limitation in that it lacks empirical data and is based on assumptions from existing studies in the literature. The limitations notwithstanding, it can be argued that some basic estimates could be useful in providing significant pointers to the policy makers. Furthermore, the robustness of the basic results can be tested using sensitivity analysis.

The above points to the need for a detailed economic analysis a control program for the prevention of foodborne illnesses including verotoxon-producing $E$. coli. This, however, requires a separate study. 


\section{REFERENCES}

1. ANZFA, 1999c. Food Safety Standards-Costs and Benefits: An analysis of the regulatory impact of the proposed national food safety reforms. Australia New Zealand Food Authority, Canberra. pp: 1-26.

2. Roberts, J.A. and P.A. Upton, 2000. E. Coli O157: H7-An Economic Assessment of an Outbreak. Luthian Health Board, Lothian, pp: 83.

3. Roberts, T. and P. Roberts, 1990. Economic Impact of Disease Caused by Listeria monocytogenes. In: A.J. Miller, L. Smith and G.A. Somkuti (Editors), Foodborne Listeriosis. Elsevier Science Publishing Company, Inc., Amsterdam, The Netherlands, pp: 137-149.

4. Roberts, J.A., P.N. Sockett and O.N. Goill, 1989. Economic impact of a nationwide outbreak of Salmonellosis: cost-benefit of early intervention. British Medical J., 298: 1227-1230.

5. Buzby, J.C., T. Roberts, C.T. Jordan Lin and J.M. MacDonald, 1996b. Bacterial Foodborne Disease: Medical Costs and Productivity losses. Food and Consumer Economics Division, Economic Research Service, US. Department of Agriculture, Washington, DC. pp: 29-50.

6. Todd, E.C.D., 1989b. Preliminary Estimates of Costs of Foodborne Disease in the United States. J. Food Protection, 52: 595-601.

7. Todd, E.C.D., 1989a. Preliminary Estimates of Costs of Foodborne Disease in Canada and Costs to Reduce Salmonellsis. J. Food Protection, 58: 586-594.

8. ANZFA, 1999a. An analysis of the regulatory impact of the proposed national food safety reforms. Australia New Zealand Food Authority., Canberra. pp: 11.

9. Anonymous, 1995a. Community outbreak of Haemolytic Uremic Syndrome Attributable to Escherichia coli 0111: NM-South Australia. Morbidity, Mortality and Weekly Report, 44: 551559.

10. Anonymous, 1995b. Community outbreak of Heamolytic Uremic Syndrome Attributable to Escherichia coli 0111: M-South Australia. Morbidity, Mortality and Weekly Report: 44: 551559.

11. Robins-Browne, R.M., E. Elliott and P. Desmarchelier, 1998. Shiga Toxin-Producing Escherichia coli in Australia. In: J.B. Kaper and A.D. O'Brien (Editors), E. Coli 0157: H7 and Other Verocytotoxin Producing E. coli Strains. American Society for Microbiology., Washington D.C. pp: 67-71.

12. WHO, 1997. Prevention and Control of Enterohaemorrhagic E. coli (EHEC) Infections. Food Safety Unit, Program on Food Safety and Food Aid, World Health Organization., Geneva, Switzerland. pp: 7-8
13. Queensland Government, 2000. Hospital Funding Model, Queensland health, Brisbane, pp: 7-17.

14. Buzby, J.C., T. Roberts, C.T. Jordan Lin and J.M. MacDonald, 1996a. Bacterial Foodborne Disease: Medical Costs and Productivity losses. Agricultural Economic Report No. 741, Food and Consumer Economics Division, Economic Research Service, U.S. Department of Agriculture., Washington, D.C. pp: 29-50.

15. Queensland Government, 2002. The Queensland Ambulance Service fees and transportation. Queensland Ambulance Service, Queensland, pp: 37.

16. Khandaker, S.A., 2003. Economic Analysis of the diseases caused by Verotoxin Producing E. Coli (VTEC) in Australia. The University of Queensland, Brisbane, Australia. 17. Cameron, C., M. Gracey and A.G. Penman,

17. 1994. Haemolytic Uraemic Syndrome in Western Australia 1980 to 1994. Australian and New Zealand J. Public Health, 20: 462-466.

18. ABS, 2001b. Australian Bureau of Statistics. Average Weekly Earnings, Australia. Accessed 28/6, 2002.

19. Landefeld, J.S. and E.P. Seskin, 1982. The economic Value of Life Linking Theory to Practice. American J. Public Health, 72: 555 - 563.

20. ABS, 2002a. Australian Bureau of Statistics. Australian Social Trends 2002: Health-National summary tables. Accessed 10/8, 2002.

21. ABS, 2001a. Australian Economic Indicators 1350.0. Australian Bureau of Statistics, Canberra.

22. ABS, 2002b. Labor Force: 6203.0. Australian Bureau of Statistics, Canberra.

23. Roberts, T. and S. Marks, 1995. Valuation by the Cost of Illness Method: The Social Costs of Escherichia coli O157: H7 Foodborne Disease. In: J.A. Caswell (Editor), Valuing food safety and nutrition. Boulder and Oxford Westview Press, New York, pp: 173-204.

24. Roberts, T., 1989. Human Illness Costs of Foodborne Bacteria. American J. Agri. Econ., 71: 468-474.

25. Buzby, J.C., J.A. Roberts, T. Roberts and P.A. Upton, 2000. Collaborative Centre for Economics of Infectious Disease. Foodborne Escherichia O157: H7 Disease Costs in the United States and Scotland. Accessed January, 2002.

26. ANZFA, 1999b. Food Safety Standards-Costs and Benefits: An analysis of the regulatory impact of the proposed national food safety reforms. Australia New Zealand Food Authority, Canberra. pp: 17. 